\title{
LIVING STRIP: FASILITAS TRANSIT DAN PASAR SEGAR KAWASAN KOTA
}

\author{
Hendri Librata ${ }^{1)}$, Suryono Herlambang ${ }^{2)}$ \\ 1) Program Studi S1 Arsitektur, Fakultas Teknik, Universitas Tarumanagara, hendrilibrata@gmail.com \\ 2) Program Studi S1 Arsitektur, Fakultas Teknik, Universitas Tarumanagara, suryonoh@ft.untar.ac.id
}

\begin{abstract}
Abstrak
Perkembangan jaman berpengaruh pada perkembangan dari kebudayaan masyarakatnya. Dalam era yang didominasi generasi milenial, konteks dalam masyarakat kota perlahan mengalami pergeseran. Mengaitkan tema milenial pada lingkungan Pasar Angke, dimana konteks hubungan pasar tradisional dan kegiatan berkomuter antar-transportasi umum darat menghasilkan dialog yang belum selesai. Pasar kehilangan makna walau transportasi umum semakin sesak dipadati. Melalui desain ini, diharapkan dihasilkan karya arsitektur yang mampu menjawab dialog lokal dari lingkungan Angke tersebut sehingga kedua fungsi mampu hidup koeksisten dan saling menguatkan. Untuk dapat memenuhi kebutuhan masyarakat milenial urban, desain menggunakan metode Mixed Program dengan memadukan unsur kegiatan transit dan imagery dari sebuah lingkungan yang segar/fresh dimana dari perpaduan tersebut dapat menciptakan pandangan baru dalam masyarakat terutama generasi milenial dalam merespon program-program yang ada sehingga memunculkan minat untuk berinteraksi dengan program-program yang disediakan dalam sebuah Living Strip. Hasil dari penelitian ini adalah sebuah strip campuran fungsi transit (KRL, metromini dan angkot), pasar tradisional buah-sayur, vertical urban farming, dan fasilitas nongkrong milenial berupa area FnB. Kemunculan program baru berupa urban farming dan fasilitas nongkrong merupakan respon untuk mengaitkan program transit dan pasar sekaligus berkonteks pada prospek kebutuhan masa depan. Merespon fungsi dan konteks lingkungan sekitar, Living Strip didesain untuk terasa segar, lapang, dan ringan sebagai suatu objek yang nyaman digunakan dalam berkegiatan sehari-hari.
\end{abstract}

Kata kunci: fasilitas transit; milenial; pasar segar; strip campuran

\begin{abstract}
Time affects the development of people's culture. In an era dominated by Millennial Generation, context in society slowly shifting. Linking millennial theme in the Angke Market environment, where the context of relationship between traditional market and public transportation produces an unfinished dialogue. The market slowly lost its meaning even though public transport crowds constantly increasing. Through this design, it is expected to produce architectural works that are able to answer the local dialogue from the Angke environment so that the two distinguished functions are able to live coexistently and mutually reinforce. To meet the needs of urban millennial society, the design used mixed programme method to combine elements of transit and imagery of fresh environment where the combination seeks new views in society, especially the millennial generation in responding the programs so that grows interest and interactions from within. The result of this study are a mixed strip between transit functions (train, metromini, and angkot), traditional fruit and vegetable markets, vertical urban farming, and millennial hangout places in the form of FnB areas. The emergence of new programs such as urban farming dan hangout facilities are responses to link transit and market program as well as contextualizing the prospects for future needs. Responding to the function and context of the surroundings, the Living Strip is expected to feel fresh, spacious, and light as an object that became norm in daily basis.
\end{abstract}

Keywords: fresh market; millennial; mixed strip; transit facilities

\section{PENDAhuluAN}

Kota terus berkembang seiring waktu dan begitu juga masyarakatnya. Setiap periode waktu membentuk karakter masyarakat sesuai dengan peristiwa yang terjadi pada masanya. Perkembangan masyarakat yang pesat membentuk kecenderungan untuk menggantikan budaya masyarakat yang lama dengan yang baru ketimbang mengadaptasinya, hal ini menyebabkan masyarakat/ lingkungan yang tidak mengganti kebiasaannya akan segera 
kehilangan maknanya dalam masyarakat sehingga pada akhirnya akan mematikan ekonomi dan value dari lingkungan masyarakat tersebut.

Sebagai bagian dari kehidupan urban perkotaan, pasar angke merupakan salah satu lingkungan yang semakin kehilangan cahayanya di dalam masyarakat. Pasar angke sejak dulu menjadi lingkungan yang dikenal atas ciri khas perdagangan buah dan sayur serta titik transportasi kereta kelas kecil. Meskipun berada di lokasi yang padat akan mobilitas urban middle-class millennials, nyatanya preferensi masyarakat telah bergeser dalam memenuhi kebutuhannya sehingga aktivitas perekonomian pasar Angke kian menurun.

Tabel 1. Komuter Jabodetabek menurut Tempat Tinggal dan Kelompok Umur

\begin{tabular}{|c|c|c|c|c|c|c|c|}
\hline \multirow{2}{*}{ Tempat tinggal } & \multicolumn{6}{|c|}{ Kelompok Umur } & \multirow{2}{*}{ Jumlah } \\
\hline & $5-14$ & $15-24$ & $25 \cdot 34$ & $35-44$ & $45-54$ & $55+$ & \\
\hline (1) & (2) & (3) & (4) & (5) & (6) & (7) & (8) \\
\hline Jakarta Selatan & 11.355 & 68.210 & 76.249 & 70.571 & 43,594 & 15,490 & 285.469 \\
\hline Jakarta Timur & 8.873 & 95.295 & 118.302 & 96.561 & 55.202 & 12.242 & 386,475 \\
\hline Jakarta Pusat & 5.953 & 30.598 & 35.533 & 27.967 & 20.487 & 6.677 & 127.215 \\
\hline Jakarta Barat & 11.005 & 75.934 & 94.797 & 93.901 & 44.421 & 18.503 & 338.561 \\
\hline Jakarta Utara & 8.431 & 45.970 & 47.512 & 31.982 & 18.065 & 13.761 & 165.721 \\
\hline Kab. Bogor & 39.962 & 137.767 & 85.394 & 85.876 & 71.999 & 6.905 & 427,903 \\
\hline Kota Bogor & 1.446 & 12.579 & 17.866 & 21.029 & 13.592 & 5.590 & 72.102 \\
\hline Depok & 29.026 & 83.965 & 82.192 & 90.375 & 59.330 & 14.637 & 359.525 \\
\hline Kab. Tangerang & 10.890 & 60.684 & 41.430 & 43.635 & 18.388 & 7.428 & 182.455 \\
\hline Kota Tangerang & 14.713 & 72.698 & 74.907 & 66.534 & 43.466 & 11.461 & 283.779 \\
\hline Kota Tangerang Selatan & 26.681 & 57.430 & 54.219 & 51.889 & 46.134 & 16.450 & 252.803 \\
\hline Kab. Bekasi & 9.373 & 61.662 & 37.223 & 72.897 & 38.833 & 4.113 & 224.101 \\
\hline Kota Bekasi & 29.895 & 102.669 & 110.845 & 102.185 & 89.422 & 25.053 & 460.069 \\
\hline Jabodetabek & 207.603 & 905,461 & 876.469 & 855,402 & 562.933 & 158,310 & $3,566,178$ \\
\hline
\end{tabular}

Sumber: BPS, 2014

Menurut statistik BPS 2014, generasi milenial dalam rentang usia produktifnya merupakan kelompok dominan dari pengguna transport umum. Keberadaan stasiun di tengah pasar menimbulkan arus pergerakan komuter dari stasiun ke Jalan Tubagus Angke untuk mencari transportasi pengumpan, dan sebaliknya. Kenyataan ini belum menjadi titik kekuatan bagi pasar angke sehingga lingkungan berpotensi untuk dikembangkan. Pengembangan strip Angke yang belum terolah dengan baik, berpotensi menghasilkan hubungan yang baru antara transit, perpasaran, dan kehidupan masyarakat sekitarnya melalui penataan sirkulasi, program, dan suasana yang mendukung. Menurut penelitian dan analisis dari InterBrandDesignForum(2015), terdapat lima kunci yang patut diperhatikan untuk memenangkan hati generasi milenial. Lima kunci tersebut adalah Create an Experience, Make It Frictionless, Offer Customization, Build Loyalty, dan Demonstrate Value.

Dalam merespon konteks kehidupan perkotaan yang dipengaruhi generasi milenial, mencoba memahami bagaimana mendefinisikan valuable bagi para generasi muda kini menjadi krusial. Berpedoman pada karakter umum milenial yang mencari pengalaman berbeda, kemudahan, dan kepraktisan, memperjuangkan nilai lokal Angke menjadi penting dikarenakan lokalitas itulah yang akan menjadi bobot bagi lingkungan di mata masyarakat jaman now.

Selanjutnya menjadi tantangan untuk mencari jawaban pengaruh perilaku milenial terhadap konfigurasi arsitektur yang dibutuhkan untuk dapat mengadaptasi citra dan guna Angke terhadap konteks perubahan jaman di kawasan perkotaan. Maka diusungkan suatu bentuk Living Strip yang merupakan integrasi fungsi yang mampu menyatukan program-program yang 
semula saling terpisah dan menjatuhkan menjadi saling membantu dan menjawab kebutuhan masyarakat milenial akan tuntutan kesejamanan dalam kehidupan berkota sehari-hari.

\section{KAJIAN LITERATUR}

\section{Urban Middle-Class Millennials}

Masyarakat urban middle-class/ kelas menengah terklasifikasi berdasarkan rentang pengeluarannya dari $\$ 2-\$ 20$ per kapita per hari. Masyarakat menengah sendiri berdasarkan pengelurannya dibedakan menjadi 3 kategori yaitu:

a. Lower Middleclass (pengeluaran \$2 - \$4)

b. Middle-Middleclass (pengeluaran $\$ 4-\$ 10$ )

c. Upper Middleclass (pengeluaran $\$ 10-\$ 20$ )

Setelah perang dunia ke 2, kelompok demografis dibedakan menjadi 4 generasi yaitu baby boomer, generasi X, generasi milenial dan generasi Z. Generasi Millennial secara teori adalah kelompok masyarakat yang lahir sekitar tahun 1981-2000. Lebih spesifiknya generasi ini berbeda dengan generasi lainnya dikarenakan faktor dan peristiwa yang menyertai generasi tersebut menjadi dominan dalam membentuk karakter umum dari masyarakatnya seperti terorisme, perkembangan pesat teknologi, internet, dan sebagainya.

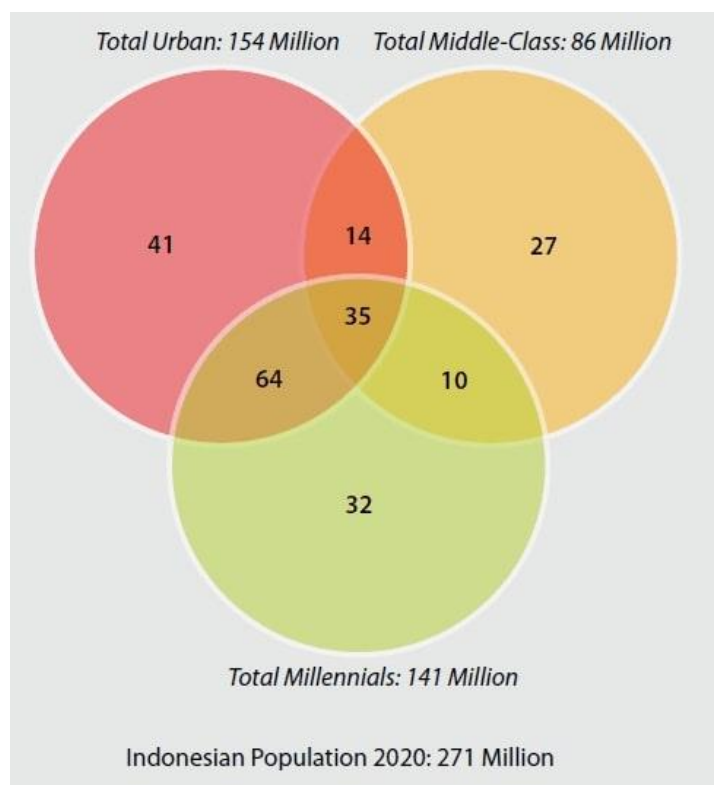

Gambar 1. UMCM terbentuk dari 3 unsur masyarakat (Urban, Millennials, Middle-Class) Sumber: Alvara Research Center, 2016

Badan penelitian Alvara Research Center memprediksi bahwa pada 2020, masyarakat Indonesia akan didominasi oleh kalangan Urban Middle-Class Millennials. Karakter dari UMCM dideskripsikan sebagai 3C, yaitu Creative, Confident, dan Connected. Persaingan hidup yang semakin ketat dan internet yang menyatukan segalanya menjadi batu asahan yang membentuk generasi untuk berpikir out of the box dan sangat aktif dalam komunikasi.

\section{Hubungan Tipe dan Perilaku dalam Arsitektur}

Mencoba mencari pendekatan arsitektur milenial terhadap lingkungan Angke dibutuhkan dasar mengenai perilaku manusia. Jon Lang dalam teorinya menyatakan bahwa perilaku manusia bekerja dalam suatu sistem, dimana beberapa faktor internal yang turut mempengaruhi adalah Perception, Cognition and Affect, dan Spatial Behavior. 


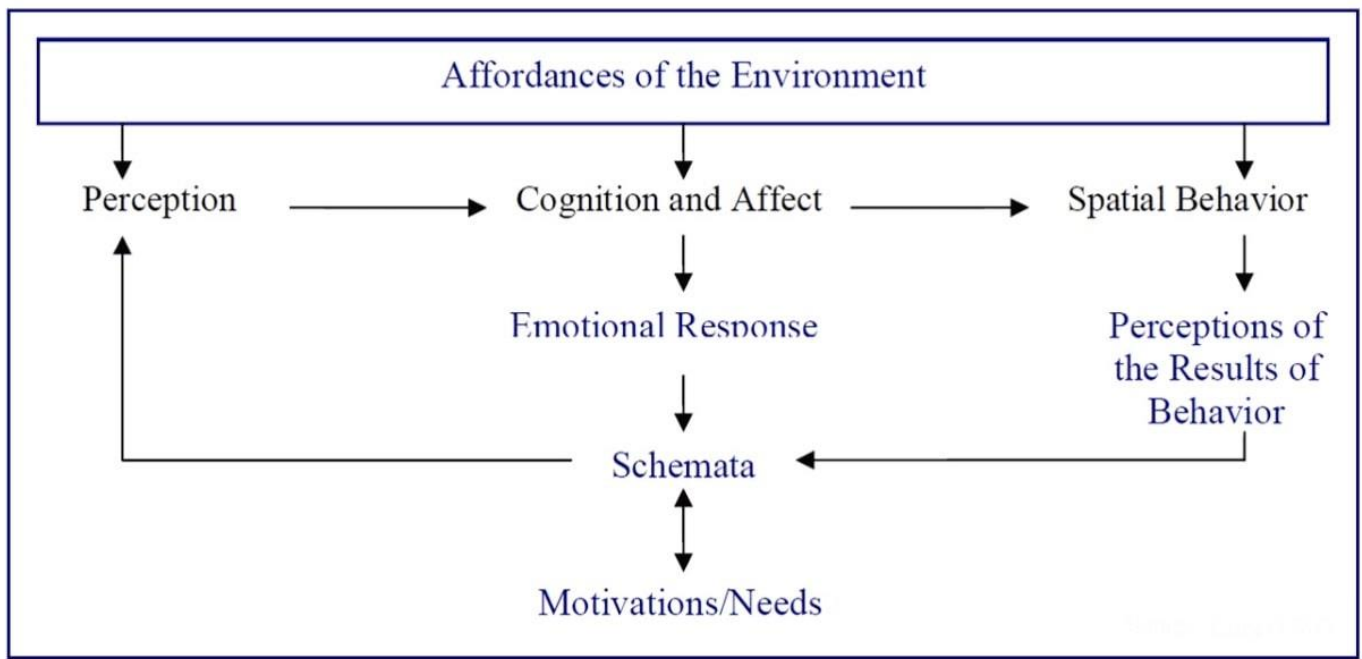

Gambar 2. The Fundamental Processes of Human Behavior Sumber: Jon Lang, 1987 (Diambil dari Moneim, 2005)

Lang dalam diagramnya berusaha menerjemahkan proses perilaku manusia dalam merespon rangsangan dari sekitarnya. Dapat dilihat bahwa respon terhadap lingkungan merupakan sebuah cycle yang timbal balik. Mengkaitkan perilaku dengan arsitektur dapat dilihat dari studi tipe dalam perkembangan sejarah arsitektur. Peranan tipe dalam arsitektur mulai bergeser dari "merepresentasikan ideologi" menjadi "mempromosikan ideologi" ketika mulai muncul gerakan-gerakan seperti Art Nouveau dan avant garde lainnya. Dengan ini dapat dikatakan bahwa tipe dan perilaku merupakan suatu hubungan timbal-balik yang berlangsung terus menerus. Perlahan arsitektur dapat membentuk persepsi baru dalam masyarakat. Ketika terdapat celah toleransi terhadap ideologi lamanya, budaya manusia dapat mengalami transformasi dan terjadi hingga sekarang. Adanya konektivitas mental antara keadaan yang sekarang dengan kebudayaan yang baru bisa membantu pikiran kita untuk terus mengingat melakukan perilaku yang baru (Hollingworth dan Barker, 2017).

Untuk dapat memasuki gerbang pikiran dan perilaku manusia, segala hal harus melalui panca indera manusia. The Gestalt School of Psychologists menyatakan pentingnya hubungan antara stimuli untuk indera yang kita buat terhadap konteks (Diambil dari Moneim, 2005: h.4). , Menjadi peran desainer dalam membentuk psikologi dan hubungan psikologi yang berkaitan dengan segala panca indera.

\section{Kontekstualitas}

Lokalitas merupakan suatu distinctiveness dan uniqueness dengan pembagian mencakup folk, work, dan place(Sugiman, 2013: h.36). Lokalitas memberikan sense of place, yaitu karakteristik yang membuat seseorang dapat merasakan dan menjadikannya sebagai identitas suatu tempat. Local distinctiveness pada dasarnya merupakan relasi manusia dan tempat. Relasi tersebut bukan hanya secara fisik namun juga mental.

\section{Studi Tipologi Fungsi}

Pasar

Tekanan untuk mengkonsentrasi aktivitas komersil sudah terjadi sejak lama. "The market hall shelters a cornucopia of delights, but the traffic and mess it generates presents a challenge to planners (Wilkinson, 2018)". Arsitektur dari pasar hanyalah menjadi panggung aktivitas ini.

\section{Stasiun Kereta Api}

Stasiun muncul sebagai hasil revolusi industri yang membawa banyak penemuan di bidang transportasi. Persepsi stasiun terbentuk dari tipologi yang membutuhkan bentang lebar dan 
otomatis menjadi landmark. Seiring waktu, image stasiun mengalami pergeseran akibat munculnya program-program pendamping yang menjadi wajah baru stasiun. Kebutuhan untuk menciptakan bangunan publik yang efisien dengan ruang internal yang luas melalui struktur bentang lebar masih terus mengkarakterkan tipologi stasiun (Mtembu, 2008).

\section{Urban Farming}

Pertanian urban muncul dalam arti memindahkan fungsi pertanian yang umumnya dilakukan di pinggiran masuk ke dalam lingkungan perkotaan. Dalam konteks kota, pertanian urban tidak hanya bertujuan untuk menghasilkan pangan dengan lebih efisien, namun juga memiliki dampak positif dari segi sosiokultur, ekonomi, kesehatan, dan lingkungan. Banyaknya sistem dan teknologi media tanam pertanian jaman sekarang memungkinkan pertanian urban bisa dibangun secara lebih fleksibel, baik dengan pencahayaan alami maupun buatan.

\section{METODE}

Penelitian ini menggunakan metode analisis kualitatif kajian literatur sebagai dasar teori dalam menentukan keputusan arsitektur yang sesuai dengan konteks milenial. Analisis berporos pada teori mengenai generasi milenial yang dikaitkan dengan teori-teori dasar mengenai fungsi dari pasar dan stasiun untuk dikaitkan dengan konteks lingkungan Angke sehingga diperoleh respon arsitektur terhadap tema milenial. Analisis tapak dan lingkungan berperan dalam mengarahkan keputusan arsitektur yang responsif terhadap kondisi sekitar untuk efektivitas dan memanfaatkan potensi yang ada.

Menggunakan dasar pemikiran dari teori Jon Lang mengenai cara kerja perilaku manusia, maka penelitian dengan wujud akhir berupa arsitektur berusaha untuk membentuk perilaku berdasarkan faktor internal yaitu Perception, Cognition and Affect, dan Spatial Behavior.

"Information about the environment is obtained through perceptual processes that are guided by schemata motivated by needs. These schemata are partially innate and partially learned. They form the linkage between perception and cognition. They guide not only the perceptual processes but also emotional responses (affect) and actions (spatial behavior), which in turn affect the schemata as the outcomes of behavior are discerned." (Lang, 1987, diambil dari Moneim, 2005)

Dalam menjawab tantangan arsitektur pada Lingkungan Angke, penelitian juga akan melakukan pengamatan dan sintesis nilai-nilai kelokalan menggunakan dokumentasi suasana Angke sebagai nilai yang khas dan tak tergantikan di tempat lain. Menggabungkan analisis antara faktor desain kesejamanan dan lingkungan, keputusan desain yang diambil akan mensintesis program yang diadakan, sifat keruangan yang diutamakan, dan karakter pengzonasian program. Pendekatan desain berusaha menggunakan metode mixed program dimana setiap program memiliki karakter ruang tersendiri, sehingga dengan adanya penggabungan tersebut, dapat terjadi penggabungan sifat keruangan yang menjadi pengalaman berbeda bagi masyarakat terutama generasi milenial. Sifat keruangan baru itulah yang berusaha membentuk faktor perception, cognition and affect, dan spatial Behavior ke arah yang lebih baik bagi keberlangsungan program yang ada di Lingkungan Angke.

\section{DISKUSI DAN HASIL}

Hasil dari penelitian ini adalah sebuah strip campuran antara fungsi transit (KRL, metromini dan angkot), pasar tradisional buah dan sayur, vertical urban farming, dan fasilitas nongkrong milenial berupa area FnB. Kemunculan program baru berupa urban farming dan fasilitas nongkrong merupakan sintesis analisis untuk mengaitkan aktivitas transit dan perpasaran sekaligus berkonteks pada prospek kota masa depan dimana kebutuhan akan pangan, hiburan, dan ruang publik urban semakin dibutuhkan. Tapak yang dipilih merupakan pengolahan kembali tapak stasiun lama dan membentang hingga muka Jl. Tubagus Angke untuk dapat membentuk 
konektivitas kegiatan sekaligus mengembalikan fungsi RTH kereta yang semula disalahfungsikan sebagai ruko. Merespon fungsi dan konteks lingkungan yang sederhana namun cukup aktif, Living Strip didesain untuk terasa segar, lapang, dan ringan sebagai suatu objek yang nyaman digunakan dalam berkegiatan sehari-hari.

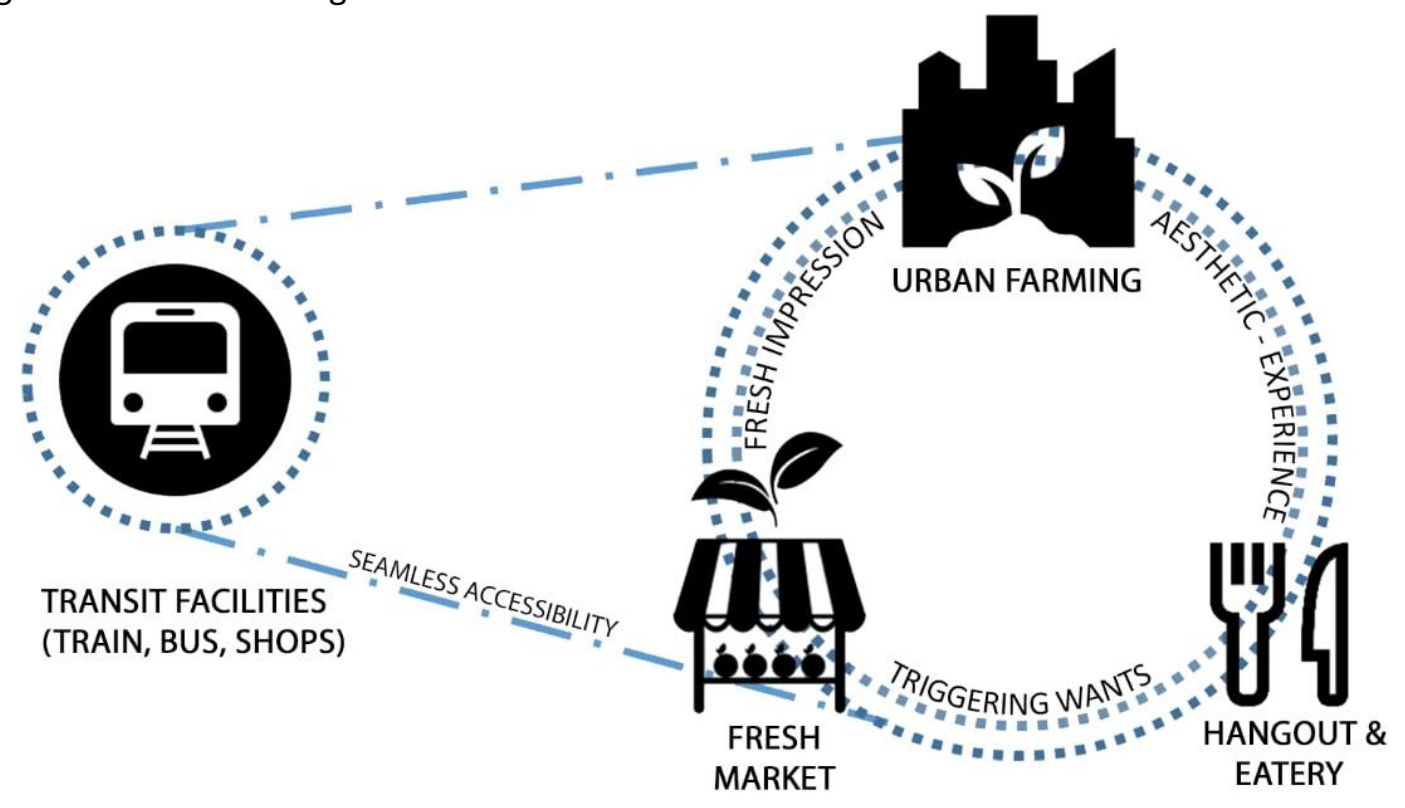

Gambar 3. Konsep Roda Hubungan Antar-Program

Sumber: Penulis, 2019

Tujuan dari penggabungan program adalah untuk menciptakan programme symbiosis dimana kombinasi program menghasilkan integrasi fungsi yang saling meredefinisi maknanya satu sama lain, sehingga bukan lagi sebagai fungsi tunggal, melainkan sebagai satu sistem yang saling menguntungkan dan mempengaruhi. Urban farming, pasar, dan tempat hangout menjadi berperan sebagai trigger aktivitas, sedangkan transit berperan sebagai trigger pergerakan. Dengan adanya ikatan rantai antara kedua faktor trigger tersebut menjadikan Living Strip mampu berjalan dengan aktif untuk menawarkan manfaatnya di sela kehidupan urban milenial.
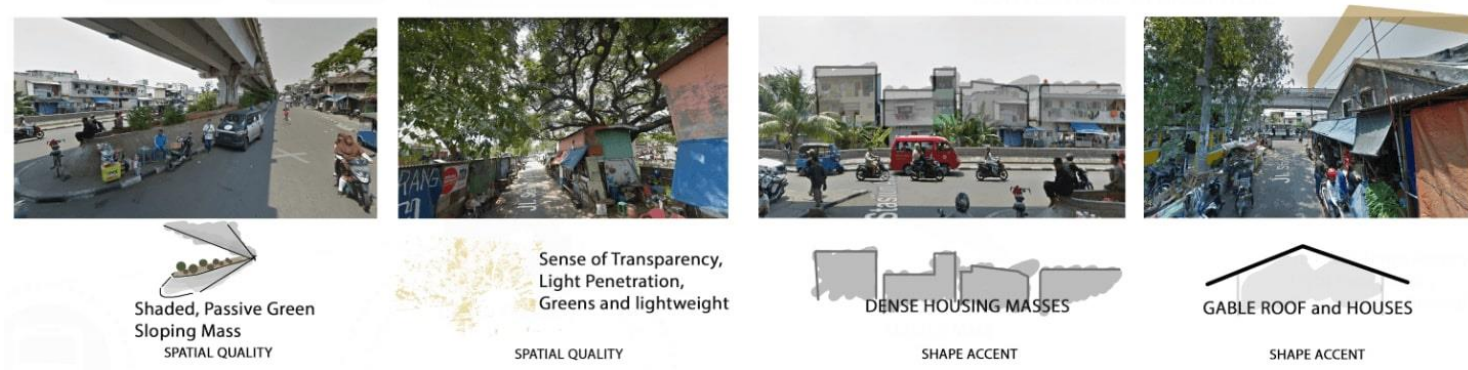

Gambar 4. Suasana Kontekstual Lingkungan

Sumber: google earth, ilustrasi pribadi

Unsur kontekstualitas diambil untuk menjadi nuansa yang tak dapat dilepaskan dari lingkungan Angke. Kontekstualitas Angke menghasilkan wujud arsitektur yang berusaha memperjuangan Genius Loci dari Angke selama ini sehingga membuatnya mampu beradaptasi dengan jaman. Dalam menanggapi keterhubungan antara fungsi transit dan pasar, terjadi penggabungan dan perubahan dari segi keruangan, sehingga setiap program mampu saling mengintervensi suasana yang ada untuk menghasilkan pengalaman yang baru dan menarik. 
Tabel 2. Program Ruang

Sumber: Penulis, 2019

\begin{tabular}{|c|c|c|c|}
\hline Zona & Nama program & jumlah & luas/ukuran \\
\hline \multirow{4}{*}{ Zona Pasar Segar } & Gudang Tenant & 58 & 108.75 \\
\hline & Zona Pedagang & 58 & 705 \\
\hline & Flexible Hall & 1 & 312 \\
\hline & Pos Timbang Ulang \& toko alat berkebun & 1 & 28 \\
\hline Zona Pasar Panen & Rak Tanaman jual & 1 & 300 \\
\hline \multirow{5}{*}{ Zona Food Tenant } & Food Tenant & 13 & 350 \\
\hline & Area makan & 1 & 380 \\
\hline & Area vertical garden $\&$ nonton bareng & 1 & - \\
\hline & ATM Center & 1 & 8.75 \\
\hline & Informal Lounge & 1 & 120 \\
\hline \multirow{2}{*}{ Zona Restoran } & Organic restaurant & 1 & 400 \\
\hline & Dapur Restoran & 1 & 140 \\
\hline & & & 2852.5 \\
\hline \multirow{11}{*}{ Zona Urban Farming } & Vertical Green House & 1 & 600 \\
\hline & Artificial Lighting Urban Farming & 2 & 1304 \\
\hline & Communal Space/Assembly Area & 1 & 80 \\
\hline & Roof Garden & 1 & 50.8 \\
\hline & Ruang persemaian & 3 & 64.5 \\
\hline & Gudang peralatan & 2 & 31.5 \\
\hline & Zona sortir hasil panen & 1 & 100 \\
\hline & Penyimpanan \& Packaging area & 1 & 100 \\
\hline & Utillitas pompa distribusi dll & & - \\
\hline & Kantor Pengelola & 1 & 124 \\
\hline & Loker \& toilet & 1 & 95 \\
\hline & & & 2549.8 \\
\hline Zona & Nama program & jumlah & luas/ukuran \\
\hline \multirow{9}{*}{ Loading \& Services } & R. Sampah basah / Kering & 1 & 28 \\
\hline & Zona exhaust \& penyimpanan gas dll & - & 90 \\
\hline & Kantor Pasar \& Penerima Loading & 1 & 200 \\
\hline & Loading Dock Area & 4 mobil & 110.5 \\
\hline & STP,WTP, Rainwater Treatment & 1 & 75 \\
\hline & Lift, Panel, AHU & - & - \\
\hline & Parkir mobil karcis & 12 & 620 \\
\hline & Parkir motor karcis & 138 & 492 \\
\hline & Musholla & 1 & 66 \\
\hline & & & 1681.5 \\
\hline Zona & Nama program & jumlah & luas/ukuran \\
\hline \multirow{4}{*}{ Hidden Street } & Minimarket & 1 & 125 \\
\hline & Coffeeshop & 1 & 90 \\
\hline & ATM Center & 1 & 9 \\
\hline & Flexible Public Space & 1 & 385 \\
\hline \multirow{3}{*}{ Zona Transit } & Selasar transit & 1 & 265 \\
\hline & Urban Courtyard & 1 & 320 \\
\hline & Multifunction Room & 1 & 85 \\
\hline & Parkir angkot & 4 & 48 \\
\hline & Parkir Ojol \& akses tepi & 8 & 30 \\
\hline Skvbridoe & Leseh: Rest and relax zone & 1 & 45 \\
\hline Skybriage & Selasar Skybridge & $3 \times 57 \mathrm{~m}$ & 171 \\
\hline \multirow{5}{*}{ Zona Stasiun } & Main Lobby & 1 & 195 \\
\hline & Loket Fisik & 1 & 15.4 \\
\hline & Self Tap gate Area & 4 & 36 \\
\hline & Kantor KAl & 1 & 50 \\
\hline & Peron Berbayar & 3 & - \\
\hline & & & 1869.4 \\
\hline \multirow{2}{*}{ Tenant Stasiun } & Tenant Barang & 31 & 478 \\
\hline & Tenant Jasa & 6 & 300 \\
\hline \multirow{6}{*}{ Loading \& Service } & Loading Dock Area & 2 mobil & 105 \\
\hline & Kantor Penerima & 1 & 16.5 \\
\hline & Gudang Sementara & 1 & 16.5 \\
\hline & Security dan panel & 1 & 32 \\
\hline & Musholla & 1 & 115 \\
\hline & Toilet \& disabled & 2 & 60 \\
\hline & & & 1123 \\
\hline \multicolumn{3}{|c|}{ GRAND TOTAL } & 10076.2 \\
\hline
\end{tabular}




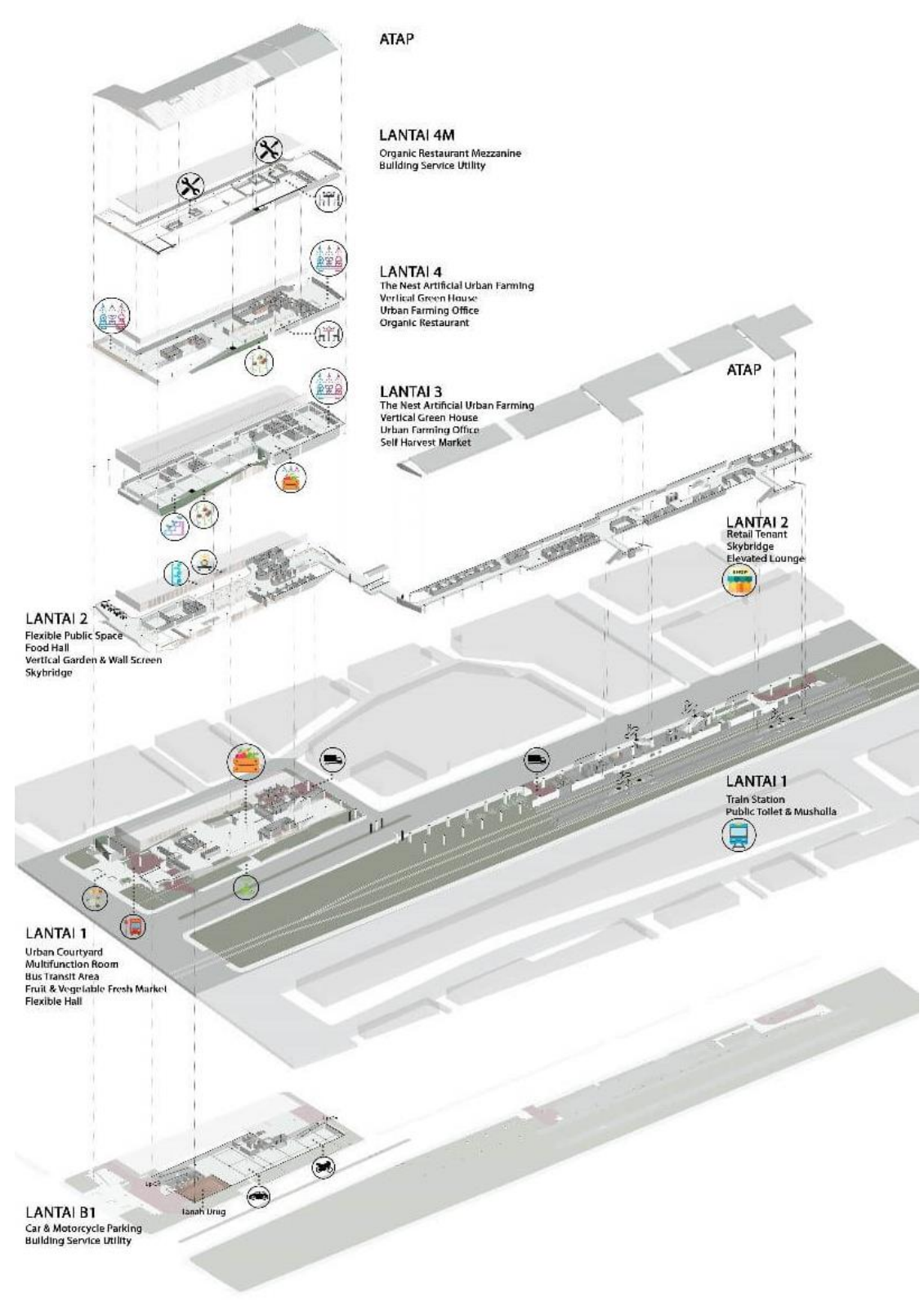

Gambar 5. Aksonometri Bangunan

Sumber: Penulis, 2019

Proyek menghasilkan dua kelompok massa yang disatukan dengan skybridge untuk menghubungkan kebutuhan fungsi transit dengan fungsi perpasaran, urban farming, dan hangout. Lantai basemen digunakan sebagai servis dan parkir untuk aktivitas park and ride dimana parkir didominasi untuk motor sebanyak 138 unit dan mobil sebanyak 12 unit. Lantai 1 dan 2 difungsikan sebagai jalur sirkulasi publik yang berhubungan dengan berbagai aktivitas komersil dan perpindahan moda transportasi, sehingga menjadi kekuatan untuk menciptakan trigger aktivitas yang menjadi perantara masyarakat milenial kota di antara rumah dan lingkungan kerjanya. Selain itu, juga akan menarik pengunjung khusus untuk datang dengan adanya tujuan berkunjung dan kemudahan akses transportasi. Urban farming pada lantai 3 dan 4 selain untuk memperoleh cahaya alami dan privasi fungsi, juga berguna menjadi crown bangunan dimana sifat keruangan dari pertanian tersebut menghasilkan nuansa transparansi tanaman pada siang hari dan permainan cahaya pada malam hari. 

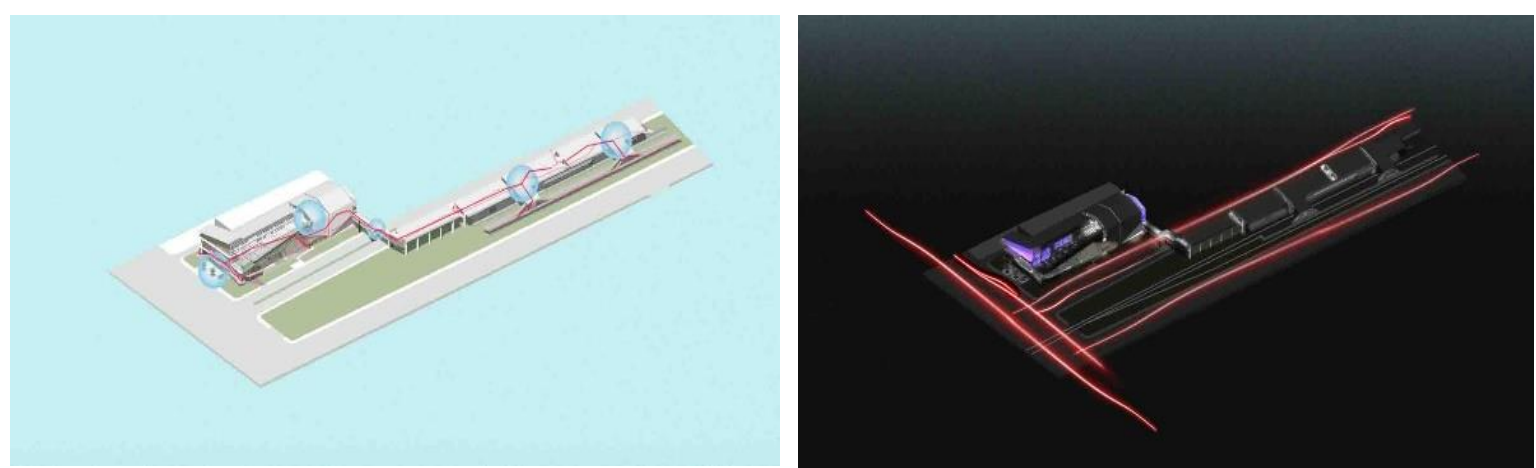

Gambar 6. Perbandingan kondisi bangunan saat siang dan malam hari

Sumber: Penulis, 2019

Program-program yang ada semuanya terkoneksi melalui satu gerakan linear untuk menghubungkan transportasi kereta pada Jl. Stasiun Angke dan kendaraan pengumpan pada Jl. Tubagus Angke. Skybridge sebagai penghubung, juga menjadi spot berhenti tersendiri sehingga setiap perpindahan memiliki intervensi-intervensi yang menghilangkan kesan "panjang dan jenuh". Dengan begitu, seluruh bagian lantai dua pada bangunan berperan besar dalam mengakomodasi sirkulasi publik yang terjadi tiap saat.

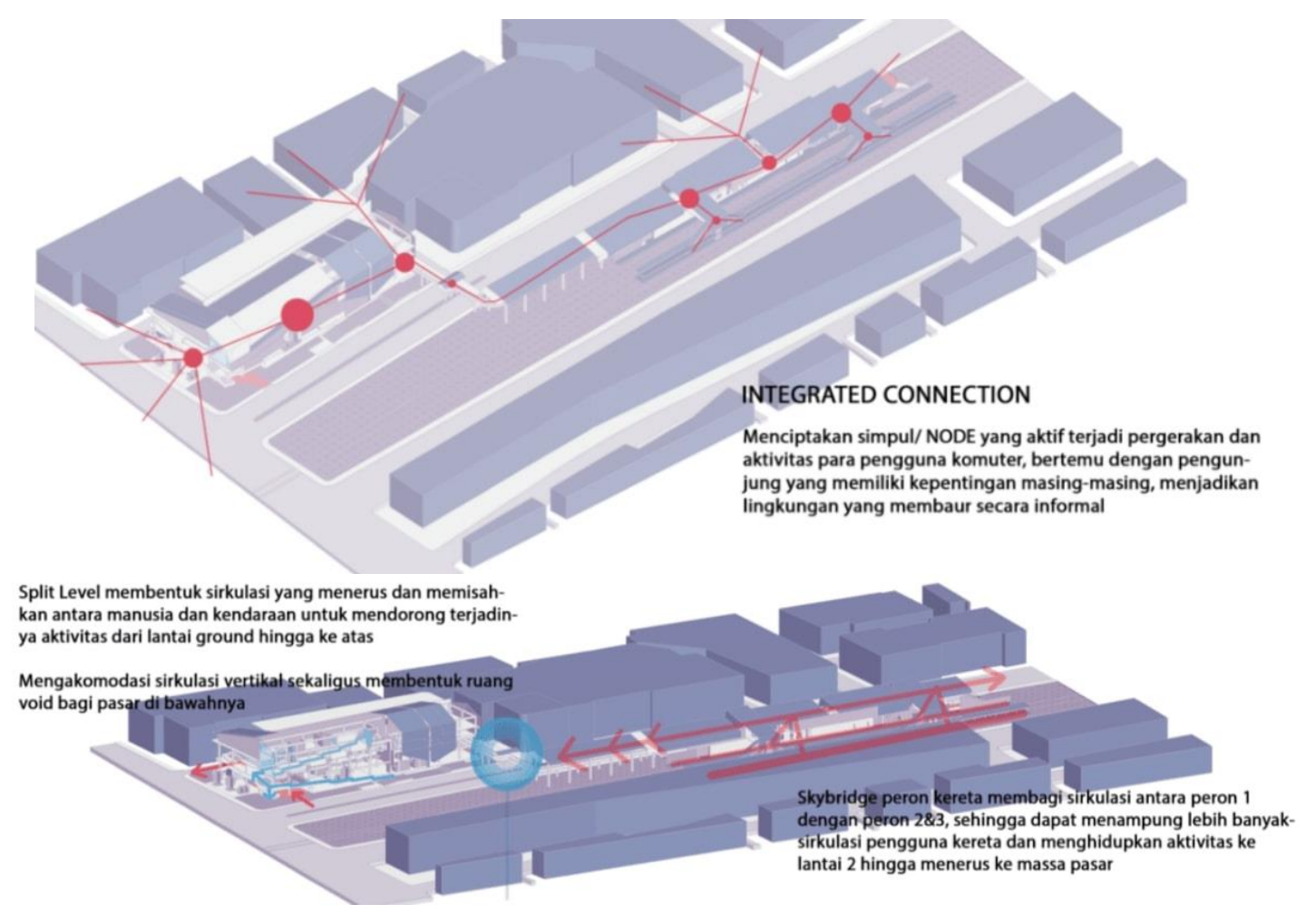

Gambar 7. Integrasi dan Node Proyek Sumber: Penulis, 2019

Sebagai respon untuk menciptakan sirkulasi program yang multi pengguna, fokus program dipusatkan pada salah satu massa menggunakan konsep split level pada lantai dasar agar tidak mengalami crossing dengan transportasi umum dasar pada area transit, juga agar mendorong sirkulasi yang lebih alami menuju lantai dua yang merupakan jalur publik (Lihat Gambar 8). Dengan adanya jalur publik tersebut, diciptakanlah berbagai titik ruang publik yang dapat dimanfaatkan untuk berbagai aktivitas/ event yang fleksibel sehingga akan semakin memicu keragaman tujuan dan aktivitas sehingga menimbulkan alasan dan ketertarikan untuk kembali. 


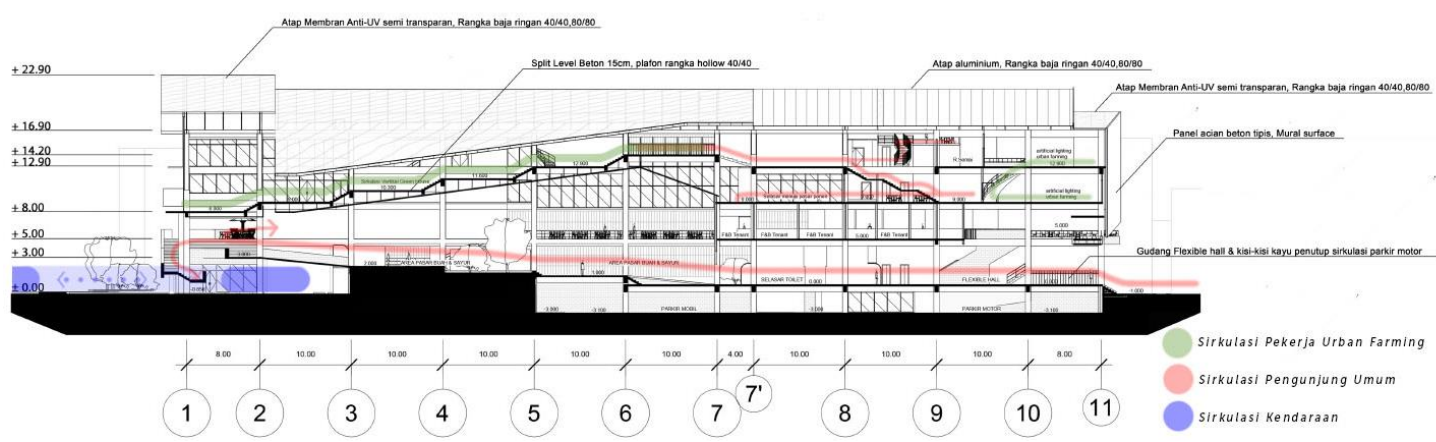

Gambar 8. Potongan Memanjang Salah Satu Massa Bangunan

Sumber: Penulis, 2019

Urban Farming menggunakan sistem hidroponik dimana media tanah tidak diperlukan dan memangkas penggunaan air hingga 90\%. Sistem dibagi menjadi 2 jenis yaitu hidroponik cahaya buatan dan hidroponik cahaya alami pada Vertical Green House. Keberadaan urban farming bukan hanya menjawab kebutuhan pangan segar perkotaan, namun juga menjadi sarana ikatan sosial melalui pekerjaan sampingan bagi masyarakat di sekitarnya, termasuk para pedagang sayur dan buah yang umumnya tidak berjualan sepanjang hari. Pergantian antara berdagang dan bertani juga berpengaruh pada transformasi ruang pasar, dimana ketika mayoritas pedagang tutup dan melakukan pekerjaan sampingan, ruang pasar dapat dimanfaatkan sementara untuk kegiatan/pedagang lain.

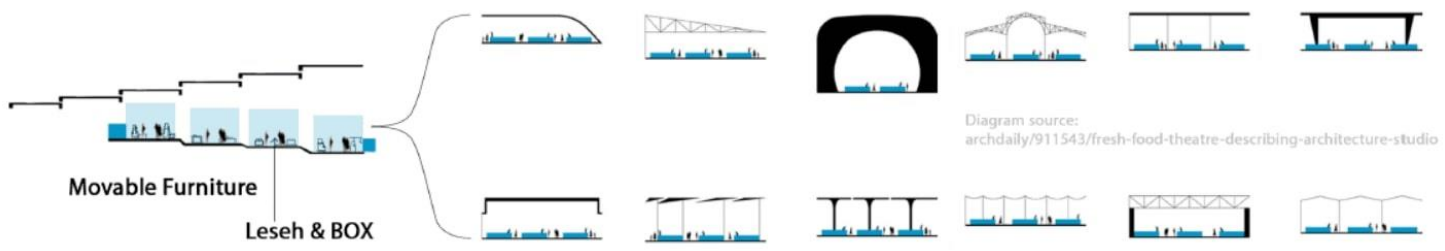

Gambar 9. Perubahan Tipologi Pasar pada Proyek

Sumber: Ilustrasi pribadi, www.archdaily.com/911543/fresh-food-theatre-describing-architecturestudio

Melihat sifat dari generasi milenial yang suka kemudahan dan variasi, respon arsitektur Living Strip harus dapat menarik minat masyarakat khususnya generasi muda seperti milenial baik dari segi pengalaman, kebutuhan, dan fasilitas yang memberikan kemudahan dan potensi untuk terus beradaptasi terhadap keinginan yang ada di dalam masyarakat. Merespon hal tersebut, menjadi penting untuk mengubah tipologi pasar yang cenderung permanen menjadi ruang fleksibel semi permanen. Model pasar yang umumnya disusun menjadi bilik-bilik yang padat dan monoton dirombak menjadi unsur gudang dan ruang dagang. Ruang dagang digunakan untuk perdagangan dengan movable furniture seperti rak geser dan gerobak, maupun dengan box-box persediaan. Konsep perdagangan yang lebih informal menyebabkan diversifikasi setiap pedagang lebih terlihat. Dengan begitu setiap pedagang dapat lebih mengeksplorasi kreativitas dalam menjajakan dagangannya.

Sifat yang fleksibel menyebabkan volume keruangan mengalir dan membaur dengan fungsi sekitarnya karena tidak memiliki batas yang tegas sehingga menghilangkan kesan fungsi yang padat dan jenuh, melainkan ikut terbawa kesan meriah, segar, dan lebih informal. Karakter ruang yang tidak mengekang dan memberi kebebasan dalam bergerak, menghasilkan kondisi ruang yang lebih santai dan kasual sehingga secara psikologis lebih aksesibel untuk dilalui oleh masyarakat sekitar, baik untuk lalu-lalang, bercengkrama, dan berbelanja dengan santai. Fleksibilitas memungkinkan adanya modifikasi atau perluasan fungsi dan event. 


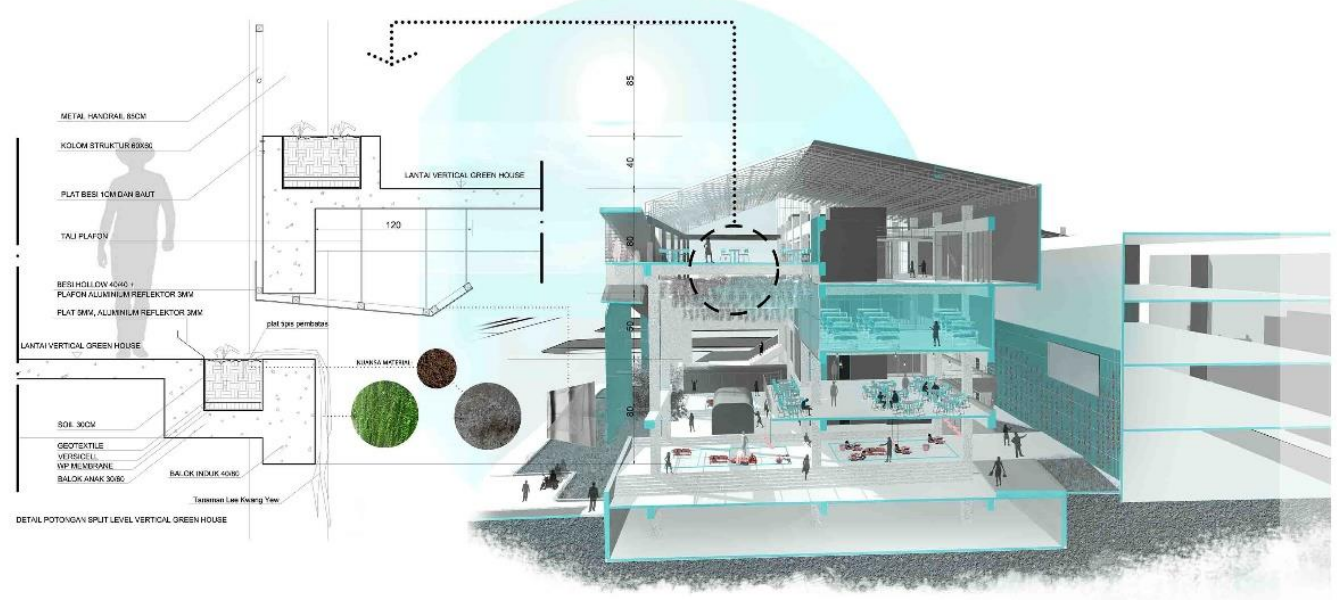

Gambar 10. Detail Suasana Potongan Perspektif Void Bangunan

Sumber: Penulis, 2019

Void utama yang menghubungkan pasar, hangout, dan sirkulasi publik memiliki peranan yang sangat penting dimana void menciptakan keruangan yang terbuka dan menyatukan keruangan setiap program secara halus serta menjadikan ruang yang kaya akan sirkulasi udara dan pencahayaan. Split level pada urban farming digunakan sebagai tangga penghijauan dan adanya panel reflektif digunakan untuk membantu memantulkan cahaya ke ruang dibawah urban farming serta menciptakan pantulan gemerlap hijau tanaman dan keramaian yang ada di bawahnya. Menghasilkan tektonika arsitektur yang sederhana namun tetap menarik menjadi penting bagi bangunan publik untuk mampu menarik perhatian masyarakat jaman sekarang terutama generasi muda seperti milenial.
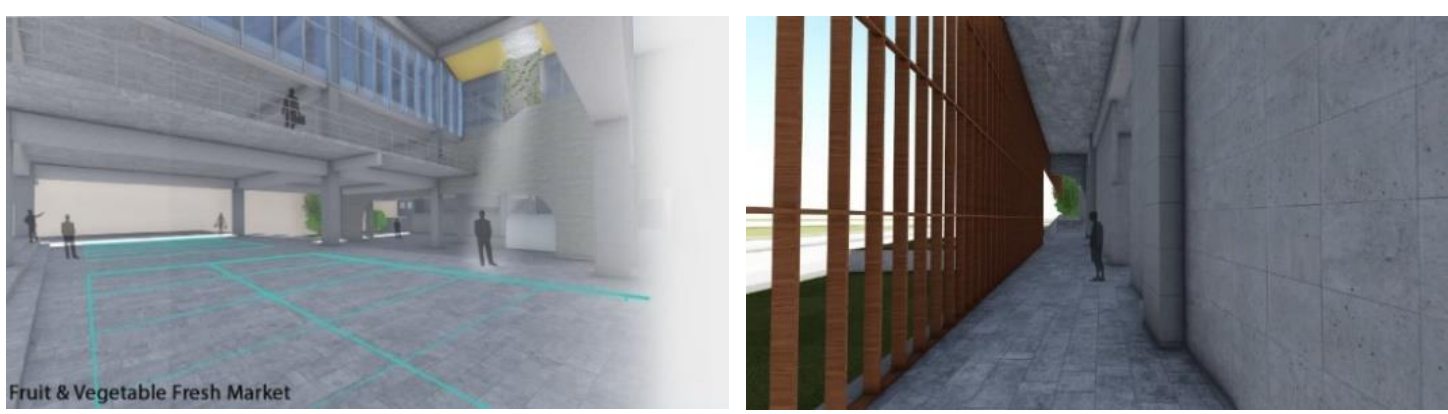

Gambar 11. Perspektif pasar dan selasar toilet Sumber: Penulis, 2019

Material yang digunakan berupa beton dan batu alam yang cenderung polos dan redup dengan sedikit sentuhan elemen kisi kayu, hal ini ditujukan agar bangunan tetap terasa ringan dan tidak melelahkan. Selain itu, material polos cenderung menjadikan warna-warni elemen dan aktivitas yang ada di dalamnya justru menjadi lebih kontras dan hidup. Dinding bangunan tetangga dimanfaatkan sebagai vertical garden untuk menjaga kualitas ruang tepi dan memperkuat suasana santai untuk aktivitas makan dan nonton bareng dari wall screen. 


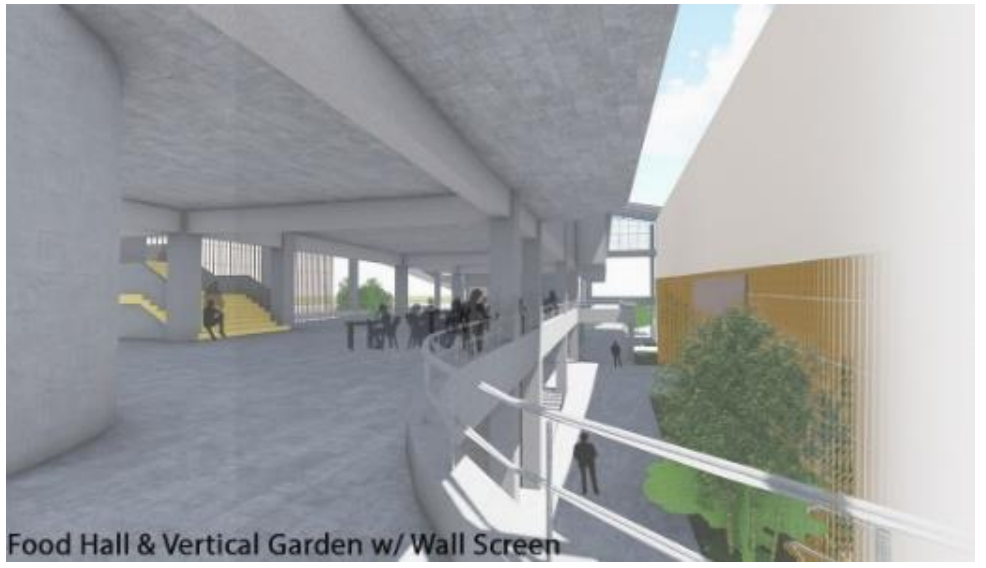

a
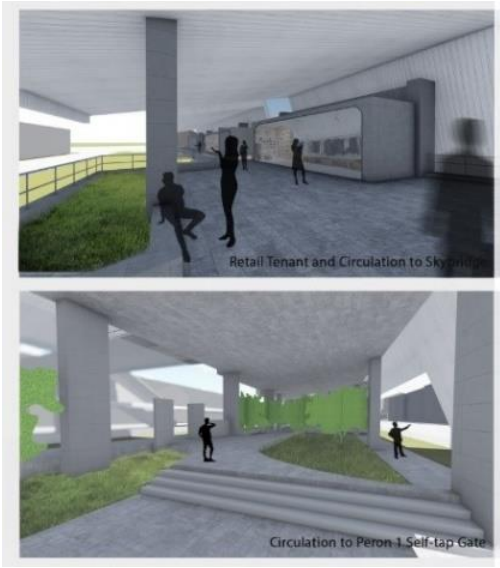

b

Gambar 12(a). Perspektif Food Hall \& Vertical Garden; 12(b). Sirkulasi stasiun Lt.1 dan 2

Sumber: Penulis, 2019

Lantai 2 area hangout berhubungan langsung dengan skybridge yang melanjutkan bangunan menuju area ritel dan stasiun. Massa stasiun dan ritel diusahakan terasa mengambang dengan ruang publik dan penghijauan di bawahnya, agar aktivitas masyarakat dapat dipadatkan hingga ke lantai 2. Sifat keruangan pada massa stasiun dan ritel dibuat menjadi ruang publik pasif, dimana lebih difokuskan pada pergerakan, istirahat sejenak, dan aktivitas yang sifatnya berputar dengan cepat.

Wujud bangunan keseluruhan merepresentasikan suatu bentuk yang berhimpitan dan menyambung sebagai bangunan yang menyatu dengan lingkungan hunian padat penduduk di sekitar Angke dengan adanya beberapa poin aksen untuk menunjukkan fungsinya sebagai wadah aktivitas. Penggabungan bentuk, material, dan tipologi menyebabkan bangunan memiliki image yang mencampur antara pasar, transit, urban farming, dan hangout. Hal tersebut berguna untuk menjadikan semua fungsi yang ada di dalam proyek sebagai program yang dominan, dan tidak ada yang bersifat pendukung atau hanya tambahan.
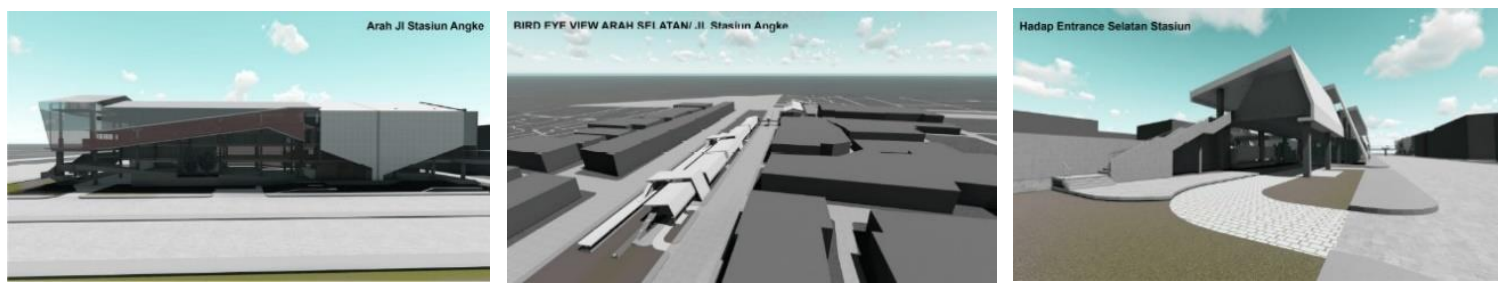

Gambar 13. Bentuk Massa Bangunan

Sumber: Penulis, 2019

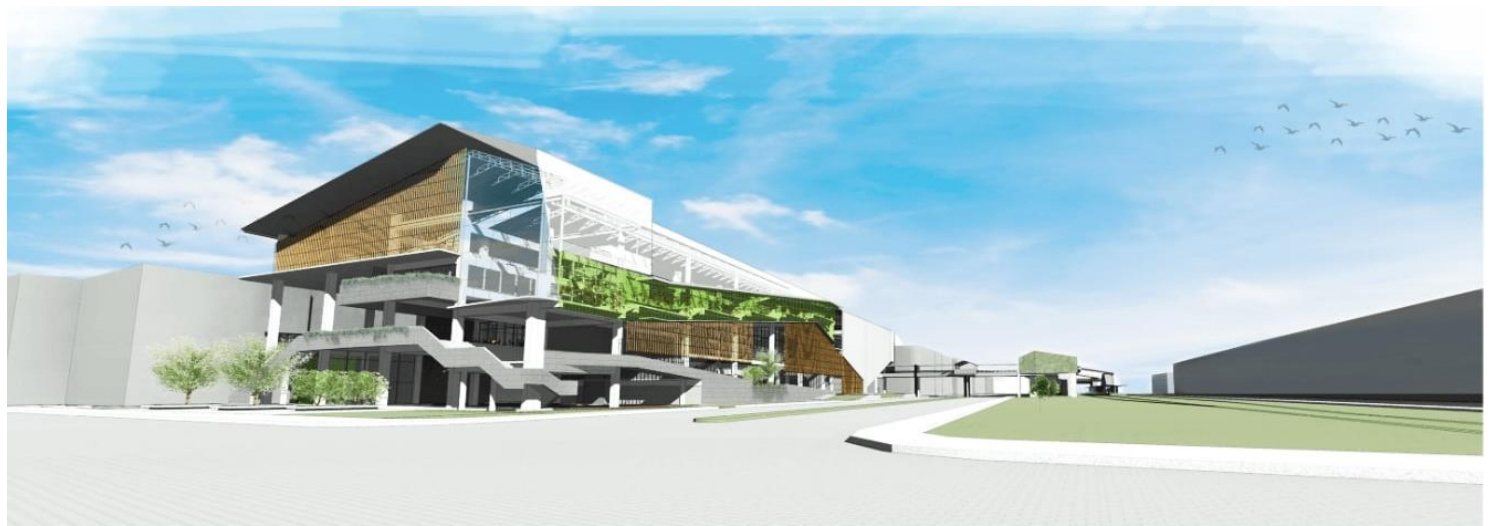

Gambar 14. Perspektif Eksterior Living Strip dari Jl. Tubagus Angke

Sumber: Penulis, 2019 
Struktur bangunan menggunakan modulasi skeleton beton bertulang untuk menciptakan kesederhanaan struktur bangunan publik. Atap menggunakan rangka baja ringan dengan penutup ACP, aluminium, dan membran anti-UV semi-transparan. Permainan bentuk atap pelana sederhana ditujukan untuk menciptakan celah-celah cahaya yang mendefinisikan ruang dibawahnya.

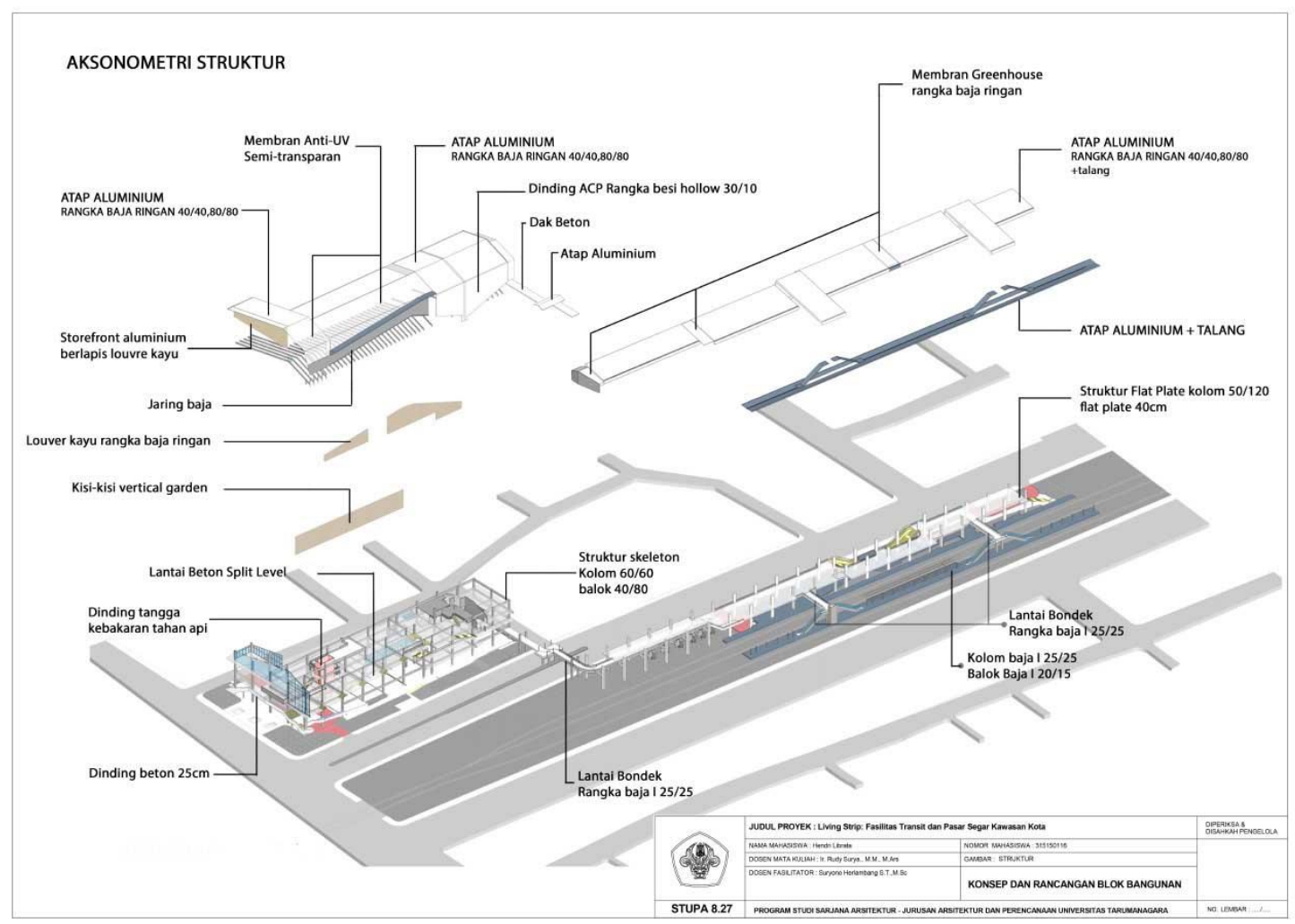

Gambar 15. Aksonometri Struktur Bangunan Sumber: Penulis, 2019

Khusus pada massa stasiun yang hanya berupa dua lantai, struktur bangunan menggunakan flat plate agar tampilan bangunan menjadi jauh lebih sederhana dan memaksimalkan ketinggian ruang lantai dasar yang ditujukan untuk ruang penghijauan dan sirkulasi publik. Untuk peron stasiun yang berupa island menggunakan struktur stasiun lama yaitu baja WF namun dimodifikasi untuk penambahan eskalator dan lift disabled.

\section{KESIMPULAN DAN SARAN}

Generasi milenial cenderung membentuk konfigurasi arsitektur ke arah yang lebih infomal dan kasual sehingga dihasilkan keruangan dengan zonasi yang lebih fleksibel dan bercampur. Respon arsitektur milenial dalam Lingkungan Angke menghasilkan suatu Strip Fungsi gabungan yang secara informal berusaha memenuhi kebutuhan masyarakat sehari-hari.Interaksi antara pengguna komuter, fasilitas hangout, pasar, dan urban farming diharapkan mampu membentuk persepsi yang positif antara setiap fungsi tersebut dan dapat mempengaruhi pola hidup masyarakatnya seperti meningkatkan keinginan berbelanja di pasar tersebut, menggunakan transport umum yang ada untuk bepergian, dan meningkatkan minat agrikultur di kota.

Hasil studi ini kemudian dapat dikembangkan untuk mempelajari lebih lanjut mengenai keterkaitan konfigurasi program arsitektur dengan perilaku, dan pengembangan lanjutan pada konteks kota yang lebih luas demi masa depan yang lebih baik, sehingga lebih baik apabila melakukan kolaborasi dengan cabang ilmu psikologi dan lainnya. 


\section{REFERENSI}

Alvara Research Center. (2016). INDONESIA 2020: The Urban Middle-Class Millennials. Jakarta: PT ALVARA STRATEGI INDONESIA

BPS. (2014). Statistik Komuter Jabodetabek (Hasil Survei Komuter Jabodetabek 2014). Jakarta: BPS

Hollingworth, C \& L, Barker. (2017). How to Use Behavioral Science to Build New Habits. Washington: WARC

InterBrandDesignForum. (2015). A New Perspective on Millennials. (Tak Diketahui): InterBrandDesignForum

Moneim, D.W.A. (2005). Architecture and Human Behavior, Does Design Affect Our Senses?. Giza: JOURNAL OF THE EGYPTIAN SOCIETY OF ENGINEERS

Mtembu, M. S. (2008). The Architecture of Railway Stations and Transportation Nodes. Durban: University of Kwazulu

Sugiman, T. (2013). Tinjauan Penerapan Lokalitas pada Bangunan Tinggi. Bandung: Universitas Katolik Parahyangan

Wilkinson, T. (2018). Typology Market Hall. Diakses 18 Januari 2019, dari https://www.architectural-review.com/essays/typology-markethall/10036729.article?blocktitle=Typology\&contentID=18909, 